\title{
Attracting Native Bees to Your Florida Landscape ${ }^{1}$
}

\author{
Rachel E. Mallinger, Wayne Hobbs, Anne Yasalonis, and Gary Knox ${ }^{2}$
}

\section{Introduction}

Florida is home to approximately 315 species of native wild bees. These bees rely on flowers for survival; their diets consist exclusively of pollen and nectar harvested from flowers. Recently reported declines in some bee species have heightened awareness of bee conservation across the United States and motivated efforts to increase floral resources for bees (Biesmeijer et al. 2006; Colla and Packer 2008; Ricketts et al. 2008; Potts et al. 2010; Burkle et al. 2013). Gardeners and land managers can aid in conservation efforts by planting flowers for bees in home or community gardens.

\section{Bee-Friendly Plants}

Generally, the best plants for bees will be those that have abundant and accessible pollen and nectar. Avoid pollenfree plant varieties (e.g., some sunflowers and lilies) because they will not provide pollen, which is the essential food source for bees. Additionally, choose plants with flat flowers or short to medium-length flower tubes (corollas), and limit plants with long flower tubes such as honeysuckle (Figure 1). Many native wild bees have relatively short proboscises, or tongues, and may not be able to access nectar from flowers with long tubes; however, flowers with long floral tubes can attract other pollinators with long tongues or beaks such as butterflies, moths, and hummingbirds.

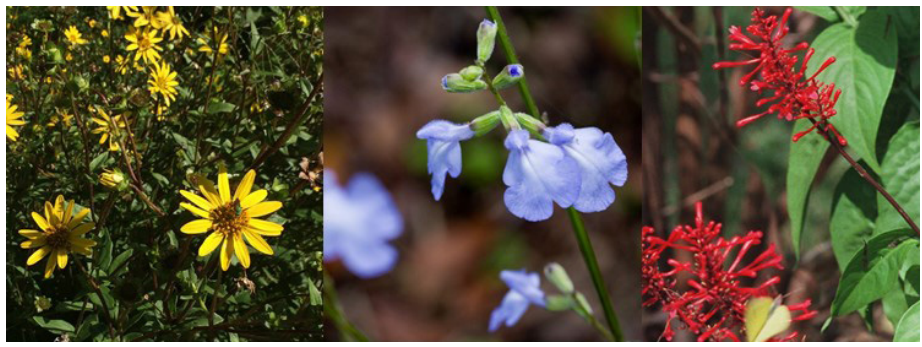

Figure 1. From left to right are examples of plants with relatively flat flowers, short-medium length flower tubes, and long flower tubes (from left to right: rosinweed Silphium sp., blue sage Salvia azurea, and firespike Odontonema cuspidatum).

Credits: R. Mallinger and UF/IFAS

Increasing the number of flowering plant species in your garden can increase the abundance and diversity of bees attracted to the garden (Kearns and Oliveras 2009; Pardee and Philpott 2014; Blauuw and Isaacs 2014). Aim for at least ten flowering plant species selected to complement one another (Williams et al. 2015; Mader et al. 2011). Specifically, design your garden to have three or more different plants blooming at any given time during the growing season, which is year-round in southern Florida, and March through November in northern areas of the state. Because bees often prefer dense floral displays, arranging flowering plants in clumps with multiple individuals per species will increase the attractiveness of the garden to bees (Blaauw and Isaacs 2014; Williams et al. 2015; Mallinger et al. 2019).

1. This document is ENY2042, one of a series of the Entomology and Nematology Department, UF/IFAS Extension. Original publication date October 2019. Visit the EDIS website at https://edis.ifas.ufl.edu for the currently supported version of this publication.

2. Rachel E. Mallinger, assistant professor, Entomology and Nematology Department; Wayne Hobbs, environmental horticulture Extension agent and master gardener coordinator, UF/IFAS Extension Clay County; Anne Yasalonis, residential horticulture Extension agent and master gardener coordinator, UF/IFAS Extension Polk County; and Gary Knox, professor, Environmental Horticulture Department, UF/IFAS North Florida Research and Education Center; UF/IFAS Extension, Gainesville, FL 32611.

The Institute of Food and Agricultural Sciences (IFAS) is an Equal Opportunity Institution authorized to provide research, educational information and other services

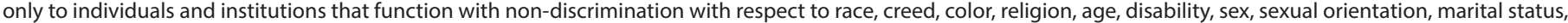
national origin, political opinions or affiliations. For more information on obtaining other UF/IFAS Extension publications, contact your county's UF/IFAS Extension office. U.S. Department of Agriculture, UF/IFAS Extension Service, University of Florida, IFAS, Florida A \& M University Cooperative Extension Program, and Boards of County Commissioners Cooperating. Nick T. Place, dean for UF/IFAS Extension. 
Additionally, bees prefer white, yellow, or blue-purple flowers (Figure 2). Orange, pink, or red flowers are not as attractive to bees (but may be attractive to other pollinators). Finally, native plants are generally best for native bees (Isaacs et al. 2009; Morandin and Kremen 2012; Pardee and Philpott 2014). While bees may collect nectar from a variety of native and non-native plants, some specialist native bees require pollen from certain native plants in order to develop optimally. Non-native plants may provide abundant nectar for bees during times, or in places, with minimal native floral resources and can be useful in combination with native plants to increase resource availability.

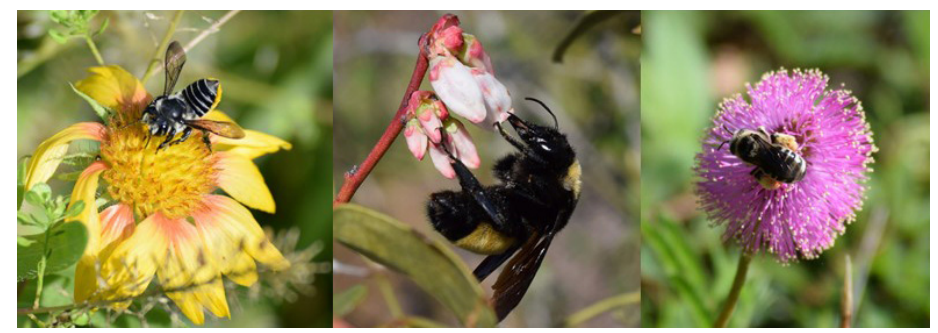

Figure 2. Flower colors that are highly attractive to native wild bees include yellow, white, and blue-purple (from left to right: blanketflower Gaillardia sp., blueberry Vaccinium sp., and mimosa Mimosa sp.).

Credits: Weaver and R. Mallinger, UF/IFAS

\section{Designing and Managing a Garden for Native Bees}

You can provide flowers for native bees by simply incorporating bee-friendly plants into your existing landscape, or you can create a special space for them in your yard by incorporating some easy design ideas (Figure 3). Create a landscape design for any garden space that you plan to make changes to, no matter how big or small. The faculty, staff, and Master Gardener Volunteers at the UF/IFAS Extension Office in your county can assist you with basic garden design concepts and may even offer classes on landscape design. Some additional elements to incorporate into your pollinator garden include:

1. Install plants of varying heights to increase visual appeal of the garden space, being sure to pay attention to the average height and width of the mature plant/tree.

2. Limit weed barriers including fabric and plastic sheets, or dense wood and straw mulches. If you do use heavy weed barriers, keep some amount of area near the bee garden free of these barriers. Many native bees nest below the ground in tunnels or cavities like abandoned rodent nests and need bare or lightly covered soil. If you see a small mound of dirt with an entrance/exit hole on top, you may have a friendly resident!
3. Add a bee nest box for the native bees that build their nests above ground (http://gardeningsolutions.ifas.ufl. edu/design/gardening-with-wildlife/pollinator-hotels. html and https://www.dropbox.com/sh/gx7lae6qx7j23ev/ AAAF-3qgh0_hV3z-gs2l-0lua/Creating\%20a\%20Pollinator\%20Hotel.pdf?dl=0).

4. Avoid pesticide use in and around your garden, especially on plants that are blooming. It is best to avoid all chemicals on plants during their bloom period, including fungicides and organic pesticides because they may harm bees that visit the flowers. If you do use pesticides during the flowering period, apply them in the evening hours, and always follow pesticide label instructions.

5. When purchasing seeds or transplants, it is best to buy ones that have not been treated with systemic insecticides such as neonicotinoids because these systemic chemicals can persist in the plant and may be present in the pollen and nectar.

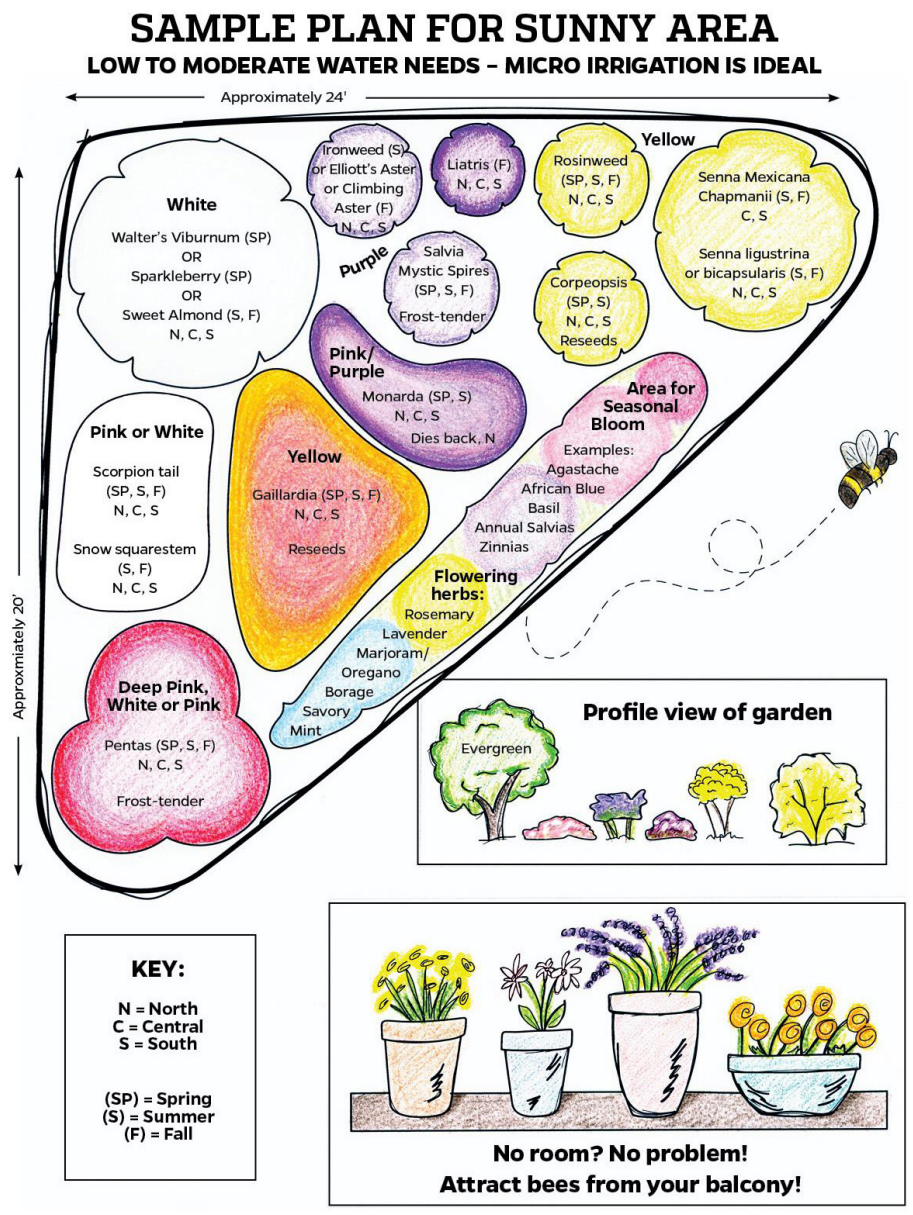

Figure 3. Example of a landscape designed to support native wild bees and other pollinators. The plants included provide attractive colors (white, yellow, and blue-purple) and ample pollen and nectar and can be grown throughout most of Florida. For each plant, information on bloom time, growing region, frost sensitivity, and flower color, is included. 


\section{Plant Recommendations for Florida}

Below are lists of plants that we recommend for native bees in northern, central, and southern Florida. These plants have floral traits expected to attract native bees, including attractive flower color, size, and shape. They also contain abundant nectar and/or pollen. While most of the suggested plants are native, some bee-attracting non-native plants are also included. This list should be used as a starting point, though it is not exhaustive. When evaluating plants for native bees, you can use the above criteria to consider plants not on this list. When choosing plants for your area, keep in mind the soil, moisture, and light requirements of the plants (https://ffl.ifas.ufl.edu/pdf/FYN_Plant_Selection_Guide_2015.pdf). Most bee-attracting plants grow in full sun, though some will thrive in partial shade.

\section{References}

Biesmeijer, J. C., S. P. M. Roberts, M. Reemer, R. Ohlemüller, M. Edwards, T. Peeters, A. P. Schaffers, S. G. Potts, R. Kleukers, C. D. Thomas, J. Settele, and W. E. Kunin. 2006. "Parallel declines in pollinators and insect-pollinated plants in Britain and the Netherlands." Science 313 351-354. DOI: $10.1126 /$ science. 1127863

Blaauw, B. R., and R. Isaacs. 2014. "Larger patches of diverse floral resources increase insect pollinator density, diversity, and their pollination of native wildflowers." Basic and Applied Ecology 15 701-711. DOI: 10.1016/j.baae.2014.10.001

Burkle, L. A., J. C. Marlin, and T. M. Knight. 2013. "Plantpollinator interactions over 120 years: Loss of species, co-occurrence, and function." Science 339 1611-1615. DOI: $10.1126 /$ science. 1232728

Colla, S. R., and L. Packer. 2008. "Evidence for decline in eastern North American bumblebees (Hymenoptera: Apidae), with special focus on Bombus affinis Cresson." Biodiversity Conservation 17 1379-1391. DOI:10.1007/ s10531-008-9340-5

Isaacs, R., J. Tuell, A. Fiedler, M. Gardiner, and D. Landis. 2009. "Maximizing arthropod-mediated ecosystem services in agricultural landscapes: The role of native plants." Frontiers in Ecology and the Environment 7 196-203. DOI:10.1890/080035
Kearns, C. A., and D. M. Oliveras. 2009. "Environmental factors affecting bee diversity in urban and remote grassland plots in Boulder, Colorado." Journal of Insect Conservation 13 655-665. DOI:10.1007/s10841-009-9215-4

Mader, E., M. Shepherd, M. Vaughan, S. Black, and G. LeBuhn. 2011. Attracting Native Pollinators. Storey Publishing, North Adams, Massachusetts, 1-385.

Mallinger, R. E., J. G. Franco, D. A. Prischmann-Voldseth, and J. R. Prasifka. 2019. "Annual cover crops for managed and wild bees: Optimal plant mixtures depend on pollinator enhancement goals." Agriculture, Ecosystems \& Environment 273 107-116. DOI: 10.1016/j.agee.2018.12.006

Morandin, L. A., and C. Kremen. 2013. "Bee preference for native versus exotic plants in restored agricultural hedgerows." Restoration Ecology 21 26-32. DOI: 10.1111/j.1526-100X.2012.00876.x

Pardee, G. L., and S. M. Philpott. 2014. "Native plants are the bee's knees: Local and landscape predictors of bee richness and abundance in backyard gardens." Urban Ecosyst 17 641-659. DOI: 10.1007/s11252-014-0349-0

Potts, S. G., J. C. Biesmeijer, C. Kremen, P. Neumann, O. Schweiger, and W. E. Kunin. 2010. "Global pollinator declines: Trends, impacts and drivers." Trends in Ecology \& Evolution 25 345-353. DOI: 10.1016/j.tree.2010.01.007

Ricketts, T. H., J. Regetz, I. Steffan-Dewenter, S. A. Cunningham, C. Kremen, A. Bogdanski, B. GemmillHerren, S. S. Greenleaf, A. M. Klein, M. M. Mayfield, L. A. Morandin, A. Ochieng, S. G. Potts, and B. F. Viana. 2008. "Landscape effects on crop pollination services: Are there general patterns?” Ecology Letters 11 499-515. DOI: 10.1111/j.1461-0248.2008.01157.x

Williams, N. M., K. L. Ward, N. Pope, R. Isaacs, J. Wilson, E. A. May, J. Ellis, J. Daniels, A. Pence, K. Ullmann, and J. Peters. 2015. "Native wildflower plantings support wild bee abundance and diversity in agricultural landscapes across the United States." Ecological Applications 25 2119-2131. DOI: $10.1890 / 14-1748.1$ 


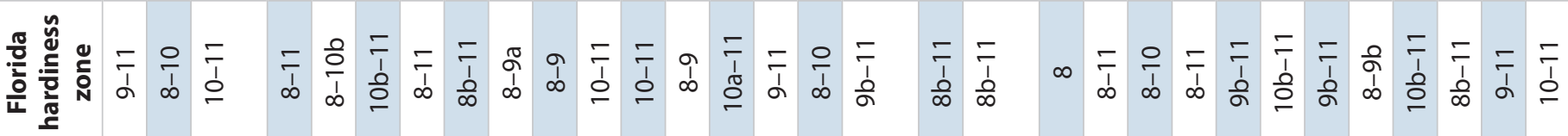

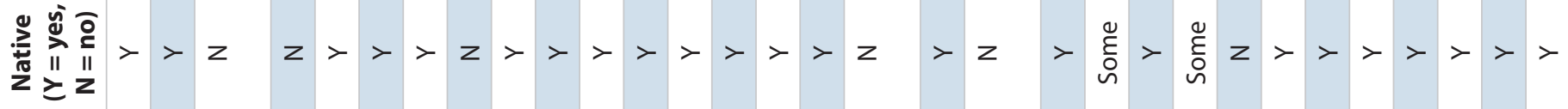
莣

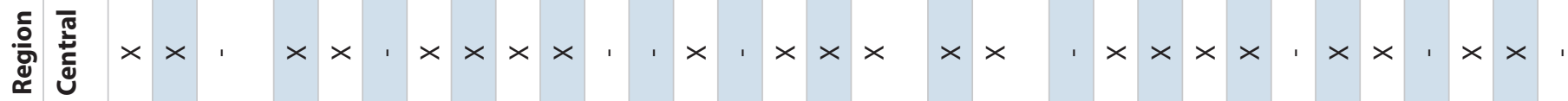

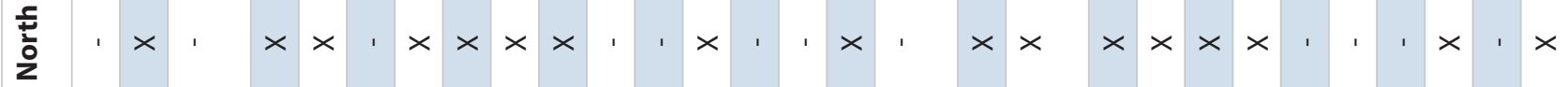

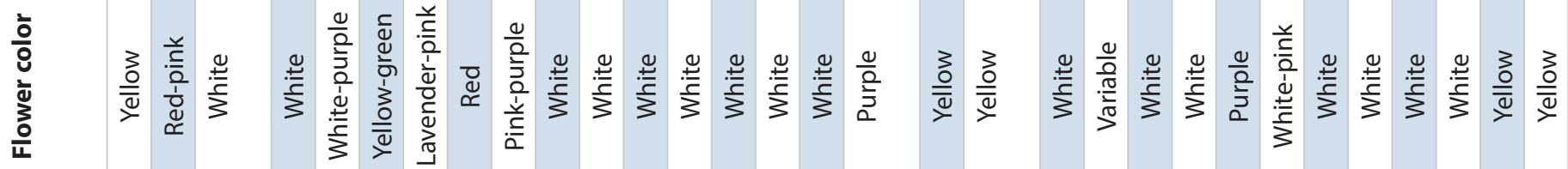
席 $\times,, \quad \times \times, \times \times,, \times \times$

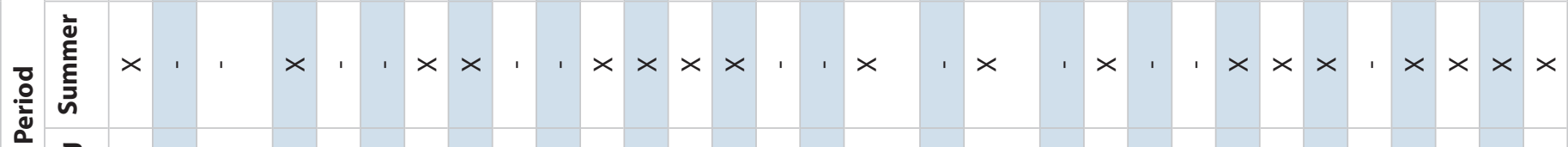
亭

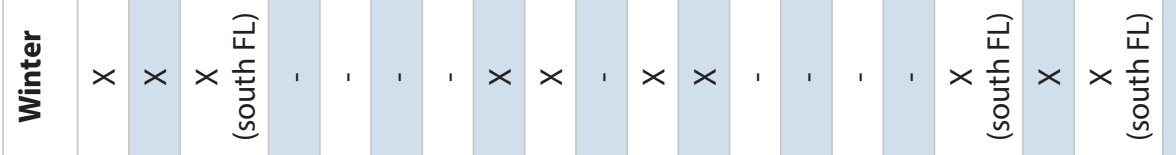
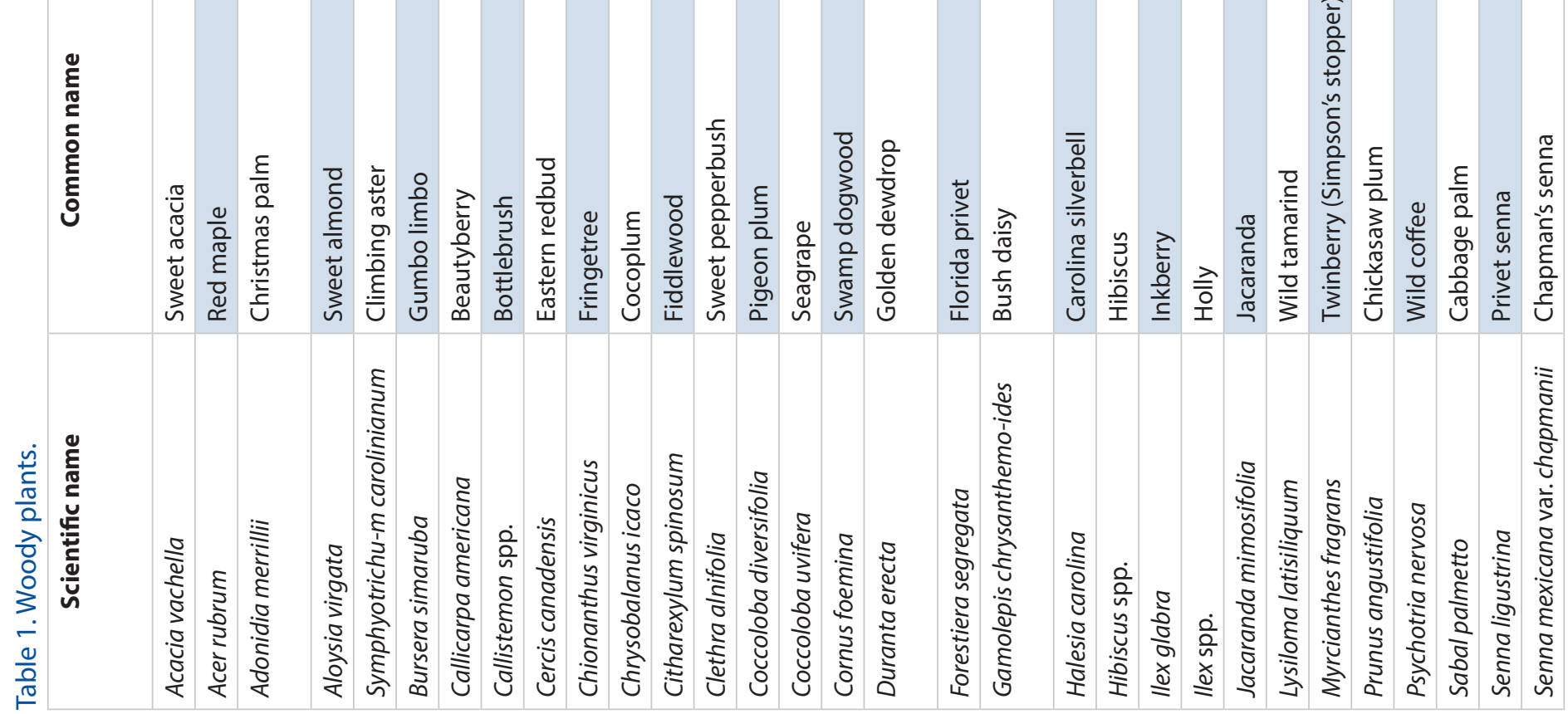


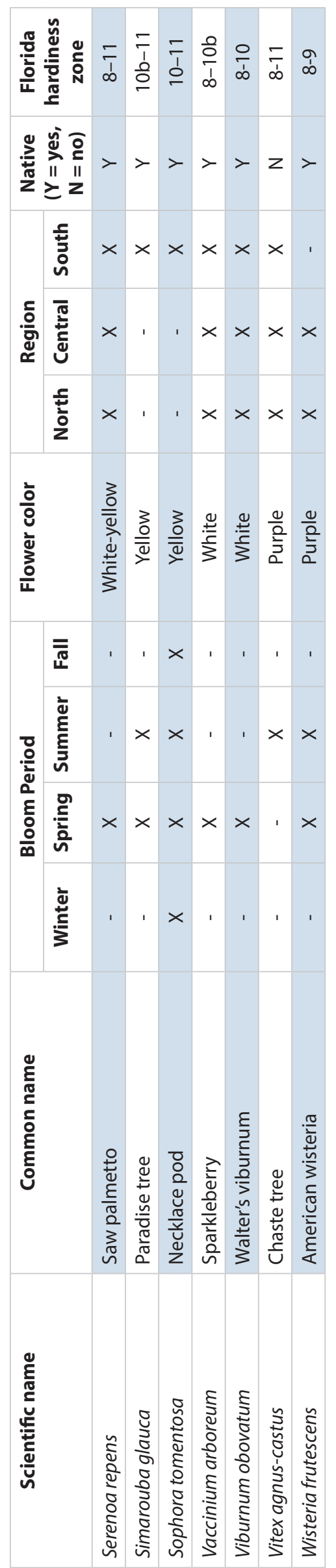




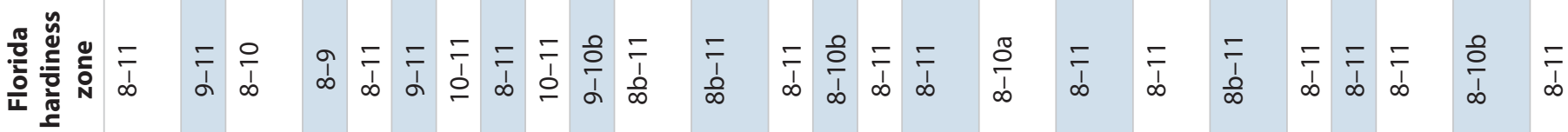

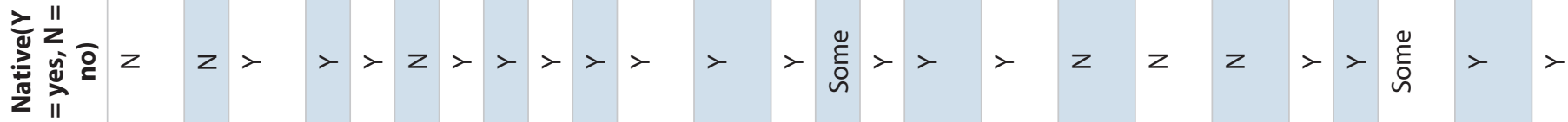

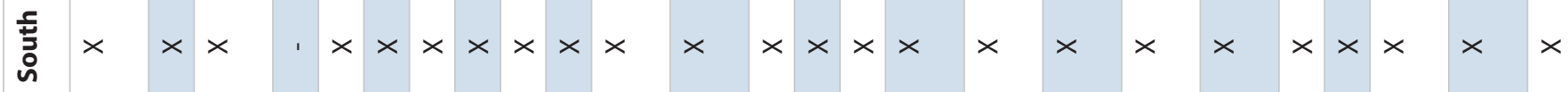

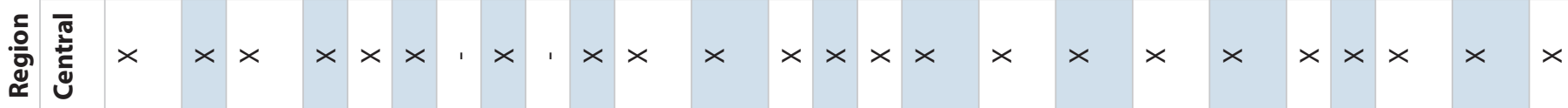
일

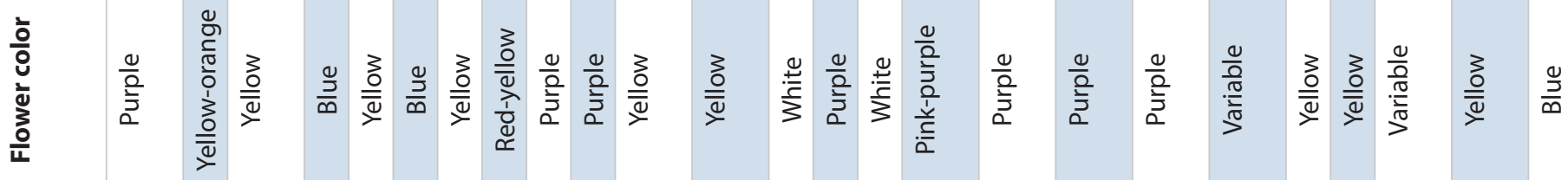

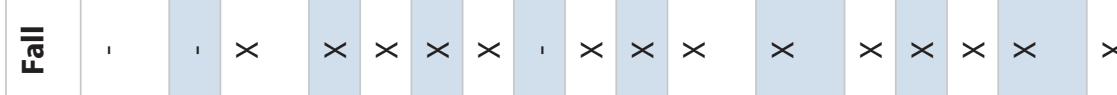

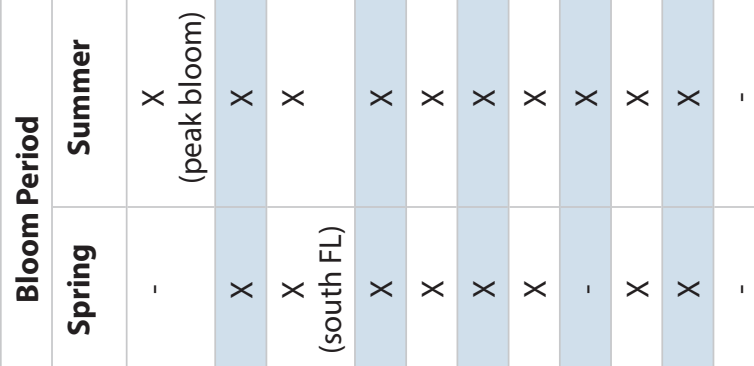

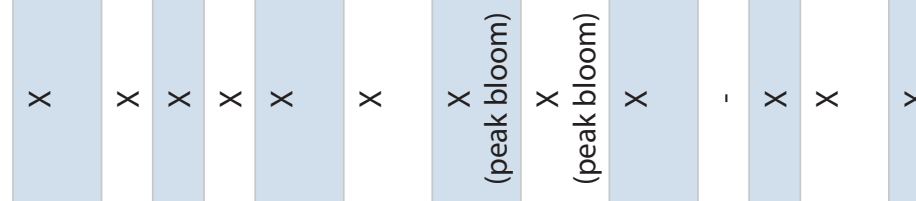

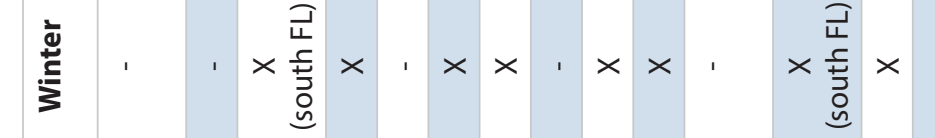

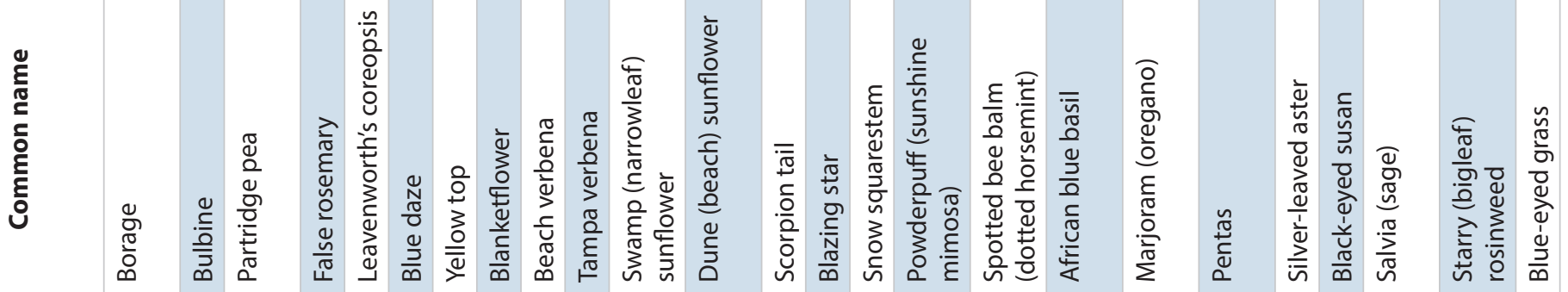
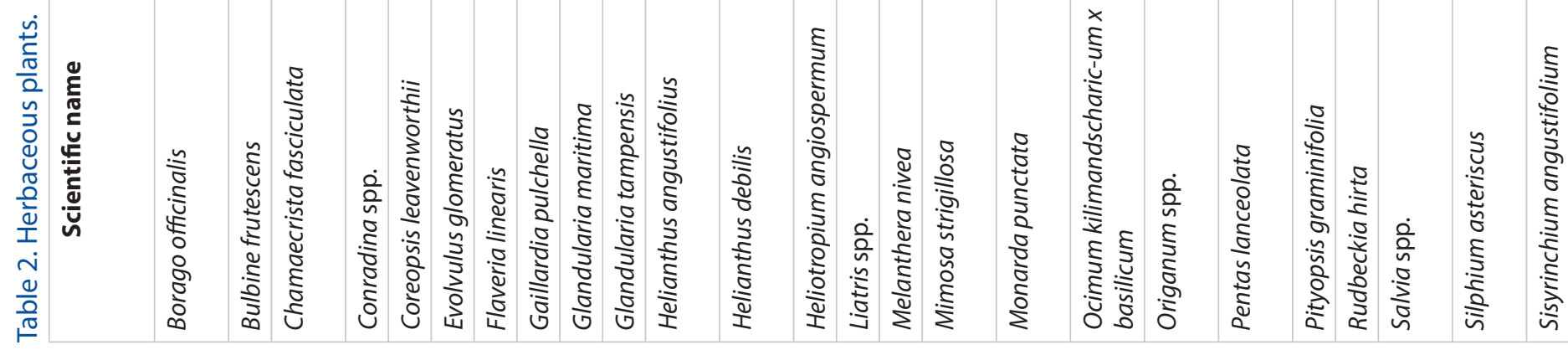


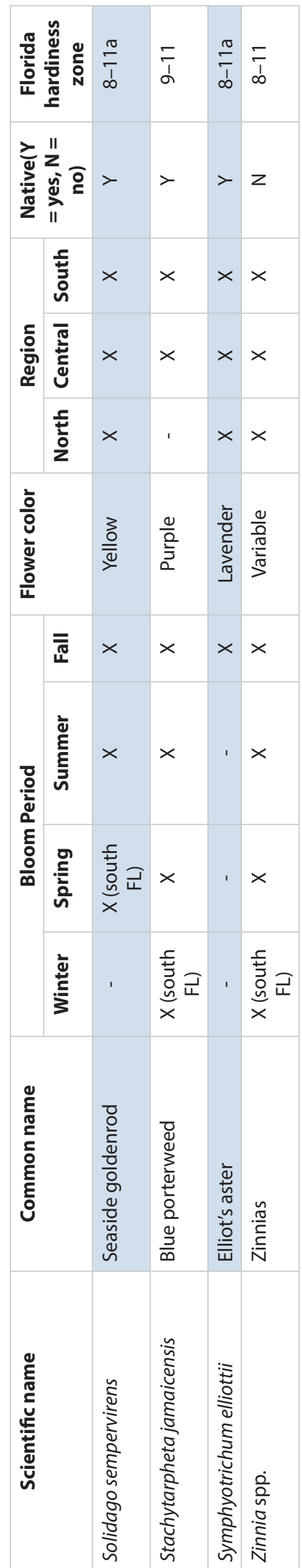

